Review Article

\title{
Knowledge and consumption of probiotics and prebiotics in India: a narrative review
}

\author{
Arshia Shireen, Mitravinda Aneesh* \\ Department of Nutrition and Dietetics, Mount Carmel College Autonomous, Bengaluru, Karnataka, India
}

Received: 05 August 2021

Accepted: 08 September 2021

\section{*Correspondence:}

Dr. Mitravinda Aneesh,

E-mail: mitravinda@mccblr.edu.in

Copyright: (c) the author(s), publisher and licensee Medip Academy. This is an open-access article distributed under the terms of the Creative Commons Attribution Non-Commercial License, which permits unrestricted non-commercial use, distribution, and reproduction in any medium, provided the original work is properly cited.

\begin{abstract}
In this narrative review, we discuss existing literature on the knowledge, consumption, and factors influencing the consumption of probiotics and prebiotics in India. We also examined the current nature of the probiotics and prebiotics market in the country. There were only a handful of studies on the knowledge and consumption of probiotics and prebiotics among Indians, mainly conducted in urban areas and middle to high-income households. Limited research showed that the knowledge of probiotics had increased appreciably in the past decade, while there is still poor technical knowledge among Indians. Simultaneously, prebiotics is an unfamiliar concept to the general public. Younger individuals are more aware than their older counterparts. The probiotics market in India offers several milk-based beverages, yogurt, and curd, while few non-dairy beverages are available from overseas. The prebiotics market in India has several powder formulas and some chewable tablets. The consumption of probiotics and prebiotics is limited to popular foods like curd, probiotic drinks, buttermilk, and milk, wheat, onion, tomatoes respectively. The modern Indian diet lacks traditional probiotic and prebiotic sources despite their presence in several regional cuisines. Furthermore, awareness of these foods and the knowledge and belief in their health benefits are the most influential factors in their consumption. Contrarily, the perception of not requiring these foods for the maintenance of good health prevents their consumption. Improving awareness and knowledge while offering diverse gut-healthy foods in all strata of Indian society can increase the utilization of these foods and improve general health and prevent chronic diseases.
\end{abstract}

Keywords: Probiotics, Prebiotics, Knowledge, Consumption, Traditional foods, Market

\section{INTRODUCTION}

The gut microbiota is a collection of all microorganisms inhabiting the human gut. The balance between an overpowering population of beneficial microorganisms and controlled pathogenic populations is the key to good digestive and general health. Probiotics and prebiotics are instrumental in maintaining this balance. Their role in the management of allergic diseases, nutrient absorption, weight reduction, and management of intestinal disorders has been widely studied. ${ }^{1,2}$ Probiotics, commonly known as gut-friendly bacteria, are live microorganisms that confer health benefits to the body when administered in adequate amounts. ${ }^{3}$ Yogurt and curd are the most commonly consumed natural probiotics in India. On the other hand, prebiotics are substrates that are selectively utilized by gut microorganisms to grant positive health effects. ${ }^{4}$ Prebiotics are generally present in various fruits, cereals, and vegetables. Commercial prebiotic supplements in the form of powders, liquids, and chewable tablets are also available in India. Additionally, several traditional gut-healthy foods rich in probiotics are also consumed in various parts of India. These include Panta Bhat, Sauerkraut, Koozhu, Ambali, Idli, Dhokla, and many more. Prebiotics are typically consumed through cereals, pulses, vegetables, and fruits in the Indian diet.

The current trends in the Indian diet reveal a shift from the consumption of natural and/or traditional foods to the consumption of highly processed convenience foods and 
fast foods. ${ }^{5}$ Such a nutrition transition alongside physical inactivity has led to higher risks of non-communicable diseases (NCDs). The present diet also impacts the diversity of resident flora and hinders their replenishment due to the westernization of diet, leading to increased lifestyle disorders. ${ }^{6}$ Therefore, the inclusion of probiotics and prebiotics can be very impactful in the prevention and management of lifestyle disorders. ${ }^{7}$ In order to promote the inclusion of these foods in the contemporary Indian diet, it is first necessary to understand the existing level of knowledge and the patterns of consumption among India's general population. This can help design interventions to enhance intestinal health by increasing awareness and utilization of probiotics and prebiotics. It can also encourage future research to attain a deeper understanding of probiotic and prebiotic consumption in India.

In view of this, we present this narrative review to ascertain the awareness, knowledge, and consumption patterns of probiotics and prebiotics among Indians. We also examine the nature of the current probiotics and prebiotics market in India. This review also highlights the ethnic food sources of probiotics and prebiotics integral to diverse Indian cuisines. Additionally, we review the various factors influencing the intake and non-intake of probiotics and prebiotics.

\section{PROBIOTICS AND PREBIOTICS MARKET}

\section{The probiotics market}

The probiotics market is fast growing on the global front. The world probiotic market was worth $\$ 36$ billion in 2003 and is estimated to reach a whopping $\$ 50$ billion in 2021 . $^{3,8}$ The United States of America has the largest probiotics market worth $\$ 1.8$ billion as of $2015 .{ }^{8}$ Three types of products currently dominate the international marketfoods with natural probiotics in them, foods fortified with probiotics, and probiotic supplements. The world probiotic market is driven by traditional probiotic foods such as yogurts, Kimchi, Kefir, and Kombucha. These products are popular in Asian, American, and European markets with more consideration given to dairy matrices for probiotic food production. ${ }^{9}$

In India too, the Probiotic market is growing exponentially. It was expected to achieve an average growth of $19.80 \%$ during 2014-19 according to the study conducted by TechSci Research. ${ }^{10}$ As per Bhupathiraju et al., the Indian Nutraceutical market was worth \$4 billion in 2017 and will reach $\$ 10$ billion by the year 2022. ${ }^{11}$ Probiotic products are likely to constitute a big part of this establishment. The most popularly used probiotic foods in India are dairybased yogurts, drinks, and ice-creams, with liquid probiotics having the biggest market.

\section{Probiotic products in the Indian market}

The Indian market is currently dominated by Amul, Nestle India, Danone, Yakult, and Mother Dairy. The market majorly has dairy-based products along with a handful of non-dairy or vegan products. All Indian products have certification from the Food Safety and Standards Authority of India (FSSAI). Popularly sold probiotic products in India include yogurt, curd, Kefir, Lassi, ice-cream, butter, buttermilk, and cheese. ${ }^{12}$ Furthermore, an online survey of probiotic products available in the online Indian market revealed various other products, of both dairy and nondairy origin. ${ }^{13}$ Dairy-based products were available as fermented beverages, yogurt, and Kefir grains while nondairy-based products were sold in the form of tea, coffee, fermented drinks, coconut water, and non-dairy yogurts. While most products were FSSAI approved, many foreign products have no certification from domestic agencies. Probiotics sold in the form of capsules are numerous and are not discussed in this review.

\section{Traditional fermented foods of India}

The Indian diet has traditionally been rich in fermented foods since time immemorial. With the advent of modern science, the benefits of many of these fermented foods as probiotics have come to light. Cereals, pulses, fruits, vegetables, milk, meat, and fish products transform beneficially upon being subjected to fermentation. Many fermented products of these foods have been understood to have a significantly high number of probiotic microorganisms. Lactic acid bacteria (LAB) and Bifidobacteria strains are the chief microorganisms found in Indian fermented foods. ${ }^{14}$

Traditional fermented foods have been identified from across India, and are found to be highly beneficial as probiotics. While foods such as Idli, Dosa, Koozhu, Ambali, Kallappam, Mor Kuzhambu, and Dahi are popular in south India, foods like Dhokla, Bhatura, Khadi, and Kanji are consumed in north India. ${ }^{14}$ North-east India is well-known for its fermented foods namely Sauerkraut, Khalpi, Kinema, Tungrymbai, Chhurpi, and Gundruk which have been discovered to confer probiotic effects to the body. ${ }^{14,15}$ These foods are made by fermenting pulses, yak's or cow's milk, vegetables, meat, and fish. Table 1 describes the many fermented foods found across India.

\section{The prebiotics market}

The prebiotics market has been gaining attention in the USA and Europe. Increasing awareness of a healthy lifestyle and gut-healthy foods has translated into greater demand for prebiotics around the world. Currently, the United States of America, Japan, the United Kingdom, France, Germany, and the Netherlands harbor the biggest prebiotic markets in the world. ${ }^{16}$ As per Mano and colleagues, the global profits of the prebiotic industry are estimated to be 10.55 billion US dollars in $2025 .{ }^{17}$

However, prebiotic products are yet to reach their full potential in terms of market size. As prebiotics is an emerging category of functional foods, there is limited information about their market characteristics in other 
parts of the world. And little to no information about its market value exists in the Indian scenario. Currently, inulin, galacto-oligosaccharides (GOS), xylo- oligosaccharides (XOS), and fructo-oligosaccharides (FOS) are the leading prebiotics that have been widely used in processed prebiotic foods. ${ }^{18}$

Table 1: Traditional fermented foods of India.

\begin{tabular}{|c|c|c|c|}
\hline S. no. & Fermented food & Ingredient(s) used & Place of origin \\
\hline \multicolumn{4}{|c|}{ I. Cereal-based fermented foods } \\
\hline 1. & Idli & Rice, black gram dal, salt & South India \\
\hline 2. & Dosa & Rice, black gram dal, salt & South India \\
\hline 3. & Dhokla & Bengal gram dal, rice, green leafy vegetables & North India \\
\hline 4. & Koozhu & Ragi flour, boiled rice, curd & Tamil Nadu \\
\hline 5. & Ambali & Ragi flour, rice & South India \\
\hline 6. & Pazhaiya Soru & Rice, curd, salt & Tamil Nadu \\
\hline 7. & Kallappam & Boiled rice, coconut toddy & South India \\
\hline 8. & Kulu & Wheat flour, buttermilk & Himachal Pradesh \\
\hline 9. & Rabdi & Flour of barley, pearl millet, corn, buttermilk & Rajasthan \\
\hline 10. & Mor Kuzhambu & Buttermilk, gram flour, vegetables & Tamil Nadu \\
\hline 11. & Bhaturu & Wheat flour and starter material & Himachal Pradesh \\
\hline \multicolumn{4}{|c|}{ II. Pulse-based fermented foods } \\
\hline 1. & Kinema & Soybeans & Darjeeling \\
\hline 2. & Tungrymbai & Soybeans & Meghalaya \\
\hline 3. & Wadi & Black gram & Punjab, West Bengal \\
\hline 4. & Wari & Black gram, soybeans & Uttar Pradesh \\
\hline 5. & Masyaura & $\begin{array}{l}\text { Black gram or green gram, Colocasia tuber, } \\
\text { radish }\end{array}$ & Sikkim \\
\hline \multicolumn{4}{|c|}{ III. Milk-based fermented foods } \\
\hline 1. & Curd & Milk & India \\
\hline 2. & Chhurpi & Yak’s milk & Arunachal Pradesh \\
\hline 3. & Chhu, Philu, Shyow & Yak's or cow's milk & Sikkim \\
\hline 4. & Mohi, Somar & Cow's milk & \\
\hline 5. & Khadi & Buttermilk or curd & Gujarat \\
\hline \multicolumn{4}{|c|}{ IV. Vegetable-based fermented foods } \\
\hline 1. & Gundruk & Leaves of cauliflower, radish, or mustard & Arunachal Pradesh \\
\hline 2. & Sinki & Radish root & North-east India \\
\hline 3. & Sauerkraut & Cabbage & India \\
\hline 4. & Soibum & Bamboo shoots & Nagaland \\
\hline 5. & Soidon & Bamboo shoots & Manipur \\
\hline 6. & Eup & Bamboo shoots & Arunachal Pradesh \\
\hline 7. & Khalpi & Cucumber & Sikkim \\
\hline
\end{tabular}

Note. Adapted from "Traditional Indian fermented foods: A rich source of lactic acid bacteria"

Table 2: Natural prebiotic sources in India.

\begin{tabular}{|lll|}
\hline S. no. & Category & Prebiotic source \\
\hline 1. & Dairy & Milk \\
\hline 2. & Cereals/grains & Wheat; quinoa; barley; oats; wild black rice \\
\hline 3. & Pulses & Green gram; black gram; red lentil; chickpeas; kidney beans \\
\hline 4. & Vegetables & $\begin{array}{l}\text { Cabbage; raw banana plantain; radish; carrot; beetroot; yam; sweet potato; } \\
\text { chicory root; ash/ bottle/ bitter/ snake gourd; pumpkin; tomato }\end{array}$ \\
\hline 5. & Fruits & $\begin{array}{l}\text { Black/ blueberries; ripe banana (Nendran, Sugandhi, Robusta); apple; } \\
\text { jackfruit; custard apple }\end{array}$ \\
\hline 6. & Condiments \& spices & Onion; garlic; ginger \\
\hline 7. & Oilseeds & Flax, chia, pumpkin, hemp seeds \\
\hline 8. & Others & Mushrooms; sugarcane juice; honey; dark chocolate \\
\hline
\end{tabular}

Note. Adapted from "Oligosaccharide profile in fruits and vegetables as sources of prebiotics and functional foods." 


\section{Prebiotic products in the Indian market}

In India, the Prebiotic Market is still in its infancy as the awareness of these products is yet to increase among the general population. The prescription of these products by nutritionists and physicians has helped disseminate information about these products but only to a fairly limited demographic. A survey of the online market found that currently, prebiotic supplements are available in different forms viz. powder and chewable tablets. ${ }^{13}$ Most of the commercial products have FOS, GOS, XOS, and inulin as major prebiotic sources, which is consistent with the global trend. There can be a cause for concern as only a few products are certified by agencies such as the FSSAI, Food and Drug Administration (FDA), or the United States Department of Agriculture (USDA). Prebiotics are also available on the online market in the form of capsules and tablets, which have not been discussed as part of this review.

\section{Natural prebiotic sources in India}

Prebiotic products are a fairly new concept for Indians, but prebiotic food is not. The Indian diet includes rich sources of prebiotics for a long time now. Very much like probiotics, the scientific knowledge and evidence of the benefits of these foods were not spelled out by tradition decades ago in India. Samanta and others had especially highlighted evidence of prebiotic consumption in the form of cereals, pulses, onions, and garlic in the Indus Valley and Vedic civilizations in 4000 BC. ${ }^{19}$ Prebiotics are a part of the Indian diet through natural foods such as milk, cereals, pulses, vegetables, and fruits.

In India, the natural sources of prebiotics available include milk, cereals like wheat, barley, wild black rice, pulses such as green- and black gram, chickpeas, vegetables like cabbage, banana plantain, gourds, tomato, and roots like beets, sweet potato, and chicory root. ${ }^{20}$ Fruits like blackand blueberries, ripe bananas (Nendran, Sugandhi, Robusta), apple, jackfruit, and custard apple are also prebiotic sources. Besides, certain other foods have also been identified as sources of prebiotics, including condiments like onion, garlic, ginger, oilseeds such as flax, and pumpkin seeds described in Table 2. Recently, seaweeds and microalgae have also been assessed to be potential sources. $^{21}$

\section{KNOWLEDGE OF PROBIOTICS AND PREBIOTICS IN INDIA}

\section{Knowledge of probiotics in India}

In India, probiotics have been gaining due attention for the past 10 years. The advent of probiotic products has been consistent with the rise in awareness in the population. ${ }^{22}$ However, there is limited research assessing the awareness and knowledge of probiotics in the Indian population. One of the earliest studies conducted in 2010 in three cities in India highlighted that $19 \%$ of the respondents could define probiotics correctly and almost $60 \%$ of respondents were not aware of probiotic foods and exhibited an unclear understanding of the term and its benefits. ${ }^{23}$

Recent studies conducted in India show a generally high level of awareness of probiotics among the free-living population. . $^{1324-27}$ However, it is important to note that these studies included predominantly younger participants aged 30 years and below from urban India. Studies conducted in Delhi have especially shown high awareness among the general public and college students. ${ }^{25,27}$ Sahib et al. on the other hand reported that almost $40 \%$ of college-goers in Chandigarh were completely unaware of the term. ${ }^{28}$ While Sharma and colleagues found a lack of awareness of brand names among college students having a high awareness of probiotics, Arora \& Prabha reported that free-living individuals with low awareness were in fact aware of the brands and products available as probiotics. ${ }^{24,27}$

Research studying the knowledge of the meaning and definition of probiotics in adults has shown that more than $90 \%$ of study participants knew the right meaning of probiotics, with consumers of probiotics exhibiting better knowledge. ${ }^{25,27,28}$ However, poor knowledge of the definition of probiotics was observed in some studies despite reporting high awareness. ${ }^{24,26}$ So far, two studies have attempted to gauge the knowledge of probiotic food sources among the general public. Arora and Prabha revealed that almost $40 \%$ of individuals knew Dahi and yogurt to be sources of probiotics. ${ }^{24}$ Another study reported that a majority (approximately 90\%) of the survey participants were aware of yogurt and curd to be probiotic sources, while $<40 \%$ were aware of other sources like millet porridges and fermented foods. ${ }^{13}$

Observational studies showed that probiotics consumers associated probiotics with gut health, diabetes management, cancer risk-reduction, prevention of intestinal infections, and improvement of heart health. ${ }^{26}$ The same study reported that less than $25 \%$ of the consumers knew the immune-enhancing benefits of probiotics. On the contrary, Shireen reported in 2021 that almost $90 \%$ of the survey participants knew the immunestrengthening benefits of probiotics, and hypothesized it to be linked to the increased awareness of immune health during the COVID-19 pandemic. ${ }^{13}$ The findings of Sharma and others in 2019 revealed that despite high awareness of probiotics in students, less than $50 \%$ knew the role of probiotics in improving intestinal health and immunity. ${ }^{27}$ We believe the unawareness of the cardiometabolic benefits of probiotics may be so because of the way probiotics are advertised and promoted in the country. Further, Sharma et al. reported that a minor percentage (approximately 25\%) of students knew the measurement unit of probiotic bacteria to be Colony Forming Units (CFU), and a majority (approximately 72\%) of them were not aware of the recommended dosage of probiotic supplements. $^{27}$ 
Sex and age seem to influence awareness levels in this matter. While Arora and Prabha revealed higher awareness in females than males, which is consistent with various studies conducted worldwide, Gnanamkonda \& Prasad reported contradicting findings. ${ }^{24,29-31}$ On the other hand, Raihing and Mageshwari found no difference in awareness between genders. ${ }^{26}$ It is noteworthy that adolescents and young adults had a higher level of awareness when compared to older participants with the exception of one study conducted in Hyderabad and Secunderabad in Andhra Pradesh wherein participants above the age of 35 years exhibited better awareness. ${ }^{24,26,31}$ It must be noted that this research only studied the awareness of probiotic ice-creams in the twin cities, unlike other studies.

The income and education levels of the participants may also influence their awareness levels. Gnanamkonda and Prasad reported that consumers engaging in professional occupations and those with a monthly income of more than $₹ 30000$ showed a higher level of awareness. ${ }^{31}$ The study suggested that high awareness in these specific groups was the result of higher health consciousness. However, it could also be the result of greater exposure to healthrelated information in the media and the supermarkets frequented by individuals belonging to this income bracket. Likewise, another study reported that urban residents had a significantly higher level of knowledge of probiotics than suburban and rural residents in India. ${ }^{13}$ The same study also found that participants with post-graduate, professional, or honors degrees had more knowledge than those with a diploma, school certificate, or less. Similarly, Gnanamkonda and Prasad also found that consumers with education in professional fields were more aware than others. $^{31}$

It is important to note the substantial increase in knowledge and awareness that has occurred in the last 10 years, especially among younger individuals. However, there is a disparity in the sample sizes of the studies included in this review. Studies on awareness and knowledge have been restricted to the urban areas of India. Adolescents and young adults showed better awareness, however, they lacked technical knowledge. Existing literature suggests that education and area of residence may influence the level of knowledge of probiotics. However, there are not enough studies conducted in this regard, due to which a challenge emerges to determine any possible trends in the relationship between sociodemographic attributes and knowledge of probiotics among Indians.

\section{Knowledge of prebiotics in India}

Prebiotics knowledge in India has not yet been studied vastly. Research on the topic began recently in the past five to six years. A handful of studies are available pertaining to the knowledge of prebiotics in the free-living Indian population, although considerable research has been done with respect to health professionals. Nevertheless, the limited evidence of prebiotics knowledge among Indians shows low awareness of the term and prebiotic products.
A recent pan-India survey found that the knowledge of prebiotics was significantly lower than the knowledge of probiotics among Indian adults. ${ }^{13}$ Similarly, another fairly recent study showed that almost $63.55 \%$ of students in Delhi who appeared to have good knowledge of probiotics, had no awareness of prebiotics. ${ }^{27}$ Another study investigating the knowledge of prebiotics among the general population concluded that participants had poor knowledge of prebiotics despite having appreciable awareness and knowledge of probiotics. ${ }^{26}$ Nonetheless, they further observed that a higher percentage of adolescents were aware of prebiotics when compared to adults and elderly participants.

About one-third of survey participants were reported to have the right understanding of prebiotics. ${ }^{26,27}$ On the other hand, Shireen reported that less than half of the participants were aware of the meaning of prebiotics, while almost a quarter of them perceived them to be products that are similar to probiotics much like the findings of Raihing \& Mageshwari who reported that more than half of the participants thought the same. ${ }^{13,26}$ The latter found that a vast majority of the respondents $(88 \%)$ perceived prebiotics as foods that enhanced general health, while a small proportion rightly perceived prebiotics as substrates to improve bacterial growth. With regard to the knowledge of prebiotics, a majority of survey participants knew prebiotics provided benefits to weight management and reduction of cholesterol, while fewer participants identified diabetes management, prevention of gastrointestinal infections and osteoporosis, and reduction of cancer risk to be benefits of prebiotics. ${ }^{26}$ However, Shireen found that most participants were unaware of the role of prebiotics in weight management and diabetes management, while they had good knowledge of the immune-boosting and digestive benefits of these foods. ${ }^{13}$ According to this study, the knowledge of prebiotics did not vary across socio-demographic characteristics.

Although Indian consumers seem to be better aware of the concept of probiotics, limited studies revealed that prebiotics were still not very widely known to the Indian population. None of the existing studies identified any differences in awareness and knowledge across sociodemographic characteristics. We believe that this uniform unfamiliarity of prebiotics across regions, age groups, genders, and income groups in India was because it is still a new concept for the general public. Awareness and knowledge must be imparted to improve the understanding of these foods. Studies suggest that nutrition education must also include probiotics and prebiotics as they are taking center stage in the management of gastrointestinal disorders and NCDs. ${ }^{24,32-34}$

\section{CONSUMPTION OF PROBIOTICS AND PREBIOTICS IN INDIA}

\section{Consumption of probiotics in India}

There is limited scientific evidence on the consumption of probiotics in India. Some studies indicated that Dahi, 
Lassi, and buttermilk were the most commonly consumed probiotic products whereas probiotic yogurt was consumed the least. ${ }^{13,25,26}$ Furthermore, probiotic drinks were consumed by less than $3 \%$ of survey takers, who were above the age of 18 years. ${ }^{26}$ Shireen also reported consumption of probiotic health drinks by less than $13 \%$ of the study participants, while almost $30 \%$ of them consumed curd daily. On the other hand, probiotic drinks and yogurt were found to be the most preferred form of probiotics among college students..$^{13,27,28}$

According to recent research, a vast majority of people consumed probiotics occasionally, while a minority consume them regularly. ${ }^{13,24}$ Additionally, more than $60 \%$ of individuals consumed probiotic drinks and Dahi on a regular basis. ${ }^{22,25}$ Another study with participants mainly belonging to south India reported regular consumption of curd, Idli, Dosa, and buttermilk. ${ }^{13}$ Furthermore, the per capita consumption of probiotic drinks was reported to be higher than probiotic Dahi in metropolitan Delhi. ${ }^{25}$ The same study highlighted that the intake of probiotic Lassi, buttermilk, and yogurt was occasional. Research also showed that middle-aged and older adults were regular consumers of probiotics. Specifically, curd consumption was significantly higher among older adults. ${ }^{13}$

Individuals in high and middle-income households were found to consume probiotics more than those from lowincome households, and high-income households were also noted to have higher usage of probiotic health drinks. $^{22,24}$ Das and colleagues reported that probiotics consumption in Delhi was highest among individuals in the middle class, followed by the upper-middle-class and the upper-class. $^{25}$ An exceptional observation was that probiotic Dahi consumption was least in the upper-class socioeconomic groups in Delhi. Additionally, one study reported that females and individuals with post-graduate and graduate degrees were found to consume probiotics more than their counterparts. ${ }^{24}$ However, it must be noted that the sample population in this study containing a higher number of males and predominantly younger participants is not representative of the general public of the country.

From the available literature, we observed that Dahi and probiotic health drinks are popular in the country, with probiotic drinks being particularly consumed in northern cities as opposed to the higher consumption of Dahi in the southern cities of India. Dahi remains an important part of meals across the country, however, other traditional and commercial foods discussed earlier are still underutilized. Additionally, there is a paucity of research to compare these recent studies, but it may not be wrong to say that the consumption of probiotics has increased with the improvement in awareness among Indians. Establishing a relationship between knowledge and consumption of probiotics among Indians through research can be quite pertinent as poor awareness and belief have been described as major factors in the underutilization of probiotic products. $^{34,35}$

\section{Consumption of prebiotics in India}

There is a paucity of scientific information about the consumption of prebiotics among Indians. So far, two studies have attempted to understand the consumption pattern of prebiotic sources in India.

Raihing and Mageshwari reported that among urbandwellers of Coimbatore, most individuals from all age categories consumed wheat and oats every week. ${ }^{26}$ Adults and the elderly were observed to consume barley on a monthly basis or occasionally. All age groups were reported to consume tomatoes and onions mostly daily, except for adolescents who consumed tomatoes weekly. Adolescents' intake of soybeans was highest, followed by the adults and elderly's, on a weekly or monthly basis. Although individuals from all age categories consumed bananas, the frequency was either monthly or occasionally. Interestingly, the adult and elderly participants were observed to consume a wider variety of prebiotic foods than adolescents.

Another study conducted by Shireen showed that onion, tomato, ginger, garlic, milk, and wheat were the most commonly consumed foods on a daily basis. ${ }^{13}$ Interestingly, milk consumption was higher among young adults than older participants. Also, the consumption of prebiotics did not differ significantly between age groups, genders, residence, or socioeconomic statuses. However, the study highlighted that consumption of prebiotics was significantly higher than the consumption of probiotics primarily due to the ease of adding prebiotic food sources to Indian meals.

More scientific information is required to accurately understand the consumption pattern of prebiotics among Indians. Quantitative studies with more diverse sources of prebiotics and involving participants from all socioeconomic groups will help gauge the adequacy or inadequacy of prebiotics consumption in the Indian population.

\section{FACTORS INFLUENCING THE CONSUMPTION OF PROBIOTICS AND PREBIOTICS IN INDIA}

A few studies have identified major reasons for the consumption and non-consumption of probiotics, but little to no scientific information is available on prebiotics.

Studies in India revealed that the primary reason for the consumption of natural and commercial probiotics was for their general and therapeutic benefits for the maintenance of health, which is consistent with several international studies. ${ }^{13,22,24,33-36}$ The belief in the health value of probiotics and existing evidence of their benefits were also factors motivating consumption. ${ }^{24}$ Individuals were also reported to consume probiotics for addressing health problems. $^{22,24}$ Gastrointestinal issues are oftentimes the only health problems addressed by probiotics commercials. Arora and Prabha described that a lack of 
side effects from probiotics consumption also enabled their intake. $^{24}$ Interestingly, they also found that the recommendation by a nutritionist or physician was a minor factor influencing intake. While some studies have shown affordability to influence consumption, other studies showed that price was not a significant factor. ${ }^{13,22,24,28}$ Shireen found that the taste of these foods was the secondmost important factor encouraging consumption, while Lakshmy and colleagues reported encouragement by selfhelp groups and consumption as a hobby to be some other reasons for intake. ${ }^{13,22}$

Findings of recent studies reported poor awareness to be the primary reason for the non-intake of probiotics. ${ }^{13,24}$ Further, the notion of lack of necessity of probiotic foods linked with a lack of awareness was noted to influence nonconsumption among Indians, which is in line with a recent study conducted by Khalesi and others in Australia. ${ }^{13,24,28,33}$ Unaffordability has also been found to prevent individuals from using probiotics, but it appears to be a minor factor. ${ }^{24,28}$ Furthermore, side effects, taste, and a general dislike of supplements were found to prevent individuals from consuming prebiotic products.

Other factors influencing the consumption of probiotic foods may pertain to the largely dairy-dominated nature of the probiotics industry. Probiotics of dairy origin can pose a challenge to consumers who experience severe lactose intolerance, those with an aversion to milk and its products, vegan consumers, children with cow's milk protein allergy (CMPA), and consumers conscious about high cholesterol content in dairy-based products. ${ }^{37-39}$

\section{CONCLUSION}

Available literature suggests that the knowledge of probiotics and prebiotics is poor among the general population in India, while the awareness of probiotics has fairly increased. The consumption of probiotics and prebiotics is limited to only a few foods that are a part of the daily diet and Indians are no longer consuming traditional probiotic and prebiotic food sources. Educated masses are more likely to be aware of the sources and benefits of these foods. However, observational studies conducted so far have a small sample size and a majority of younger participants and those belonging to middle- or high-income households. Studies with a larger sample size focusing on participants from suburban and rural areas as well as those from different socioeconomic strata can give a clearer picture in this matter. Efforts should also be made to explore and popularize the forgotten traditional foods with probiotics and prebiotics. Consumption of indigenous sources is likely to be more economical than consuming commercial products or supplements. Therefore, awareness programs and advertisements regarding probiotics and prebiotics must become mainstream and shed light on the benefits of these foods beyond gastrointestinal health, with emphasis on the revival of traditional foods.
Funding: No funding sources Conflict of interest: None declared Ethical approval: Not required

\section{REFERENCES}

1. Kerry GR, Patra JK, Gouda S, Park Y, Shin HS, Das G. Benefaction of probiotics for human health: A review. Journal of Food and Drug Analysis. 2018;26(3):927-39.

2. Pandey KR, Naik SR, Vakil BV. Probiotics, prebiotics and synbiotics- a review. Journal of Food Science and Technology. 2015;52(12):7577-87.

3. de Simone C. The Unregulated Probiotic Market. Clinical Gastroenterology and Hepatology. 2019;17(5):809-17.

4. Hill C, Guarner F, Reid G, Gibson GR, Merenstein DJ, Pot B et al. The International Scientific Association for Probiotics and Prebiotics consensus statement on the scope and appropriate use of the term probiotic. Nature Reviews Gastroenterology \& Hepatology 2014;11:506-14.

5. Raza A, Kalaivani K, Ramachandran P. Nutrition transition in India: Overview of dietary intake and nutrition status (2000-Present). Advances in Food Security and Sustainability. 2019;4:175-91.

6. de la Cuesta-Zuluaga J, Corrales-Agudelo V, Velásquez-Mejía E P, Carmona JA, Abad J M, Escobar JS. Gut microbiota is associated with obesity and cardiometabolic disease in a population in the midst of Westernization. Scientific Reports. 2018;8(1):1-14.

7. Noce A, Marrone G, Di Daniele F, Ottaviani E, Jones WG, Bernini R et al. Impact of Gut Microbiota Composition on Onset and Progression of Chronic Non-Communicable Diseases. Nutrients 2019;11(5): 1073 .

8. Paraskevakos G. Market insights on probiotics. Prebiotics/Probiotics. 2016;27(5). Available at: https://www.teknoscienze.com/tks_article/marketinsights-on-probiotics/. Accessed on 20 July 2021.

9. Dey G. Non-dairy Probiotic Foods: Innovations and Market Trends. Innovations in Technologies for Fermented Food and Beverage Industries. 2018;159-73.

10. TechSci research. India Probiotic Market Forecast and Opportunities. Research and Markets. 2014. Available at: https://www.researchandmarkets. com/research/b7c3nq/india_probiotic. Accessed on June 25, 2021.

11. Bhupathiraju K, Krishnaraju AV, Sengupta K, Golakoti T, Akolkar SK, Datla P. Regulations on nutraceuticals, functional foods, and dietary supplements in India. Nutraceutical and Functional Food Regulations in the United States and around the World. 2019;445-64.

12. Arora M, Kaur N, Arora M, Bansal P. Critical Review on Food Safety Standard Regulations: A Real Scrutinizing Authority or a Misleading Player for Probiotic Products. Applied Clinical Research, Clinical Trials and Regulatory Affairs. 2018;6(2):71-85. 
13. Shireen A. Knowledge, Consumption and Perception of Probiotics and Prebiotics among Indian Adults. 2021. Unpublished Masters Dissertation. Mount Carmel College, Autonomous, India.

14. Kumar SR, Kanmani P, Yuvaraj N, Paari KA, Pattukumar V, Arul V. Traditional Indian fermented foods: A rich source of lactic acid bacteria. International Journal of Food Sciences and Nutrition. 2013;64(4):415-28.

15. Chaudhary A, Sharma DK, Arora A. Prospects of Indian traditional fermented food as functional foods. Indian Journal of Agricultural Sciences. 2018;88(10):1496-501.

16. Panesar PS, Bali V, Kumari S, Neha Babbar Brar SK, Dhillon GS, Soccol CR. Biotransformation of Waste Biomass into High Value Biochemicals. 2014;9781461480:1-504.

17. Mano MCR, Neri-Numa I A, da Silva JB, Paulino B N, Pessoa MG, Pastore G M. Oligosaccharide biotechnology: an approach of prebiotic revolution on the industry. Applied Microbiology and Biotechnology. 2018;102(1):17-37.

18. Saville BA, Saville S. Xylooligosaccharidesand Arabinoxylanoligosaccharides and Their Application as Prebiotics. Applied Food Biotechnology. 2018;5(3):121-30.

19. Samanta AK, Kolte AP, Senani S, Sridhar M, Jayapal N. Prebiotics in ancient Indian diets. Current Science. 2011;101(1):43-6.

20. Thammarutwasik P, Hongpattarakere T, Chantachum $\mathrm{S}$, Kijroongrojana K, Itharat A, Reanmongkol W, Tewtrakul S, Ooraikul B. Prebiotics - A Review. Songklanakarin Journal of Science. 2009;31(4):4018.

21. Raposo MFDJ, Morais AMMB De, Morais RMSC De. Emergent sources of prebiotics: Seaweeds and microalgae. Marine Drugs. 2016;14(2):1-27.

22. Lakshmy G, Seetha Devi B, Ramesh B. The blooming prospects of probiotic products in India. International Journal of Recent Technology and Engineering. 2018;7(4):253-8.

23. Kumar M, Goyal R, Khandal H, Khilwani A, Gupta $\mathrm{S}$, Lomash $\mathrm{H}$ et al. Perception and attitudes of Indian consumers to probiotic foods. International Journal of Probiotics and Prebiotics 2010;5(4):217-20.

24. Arora, Prabha K. Consumer awareness and willingness to purchase probiotic food and beverage products: a study of Sonipat district, Haryana awareness. British Food Journal. 2020.

25. Das J, Raju R, Sirohi S, Chandel BS, Raju PN, Meena BS. Consumption pattern of fermented probiotic dairy Products in metropolitan Delhi. Journal of Pharmacognosy and Phytochemistry. 2019;8(1):45-9.

26. Raihing C, Mageshwari US. Consumer Knowledge and Awareness of Prebiotic and Probiotic Foods. International Journal of Scientific Research and Reviews. 2014;3(4):91-104.

27. Sharma R, Gupta S, Gupta D, Kumar P. Awareness and Knowledge about Probiotics among College
Students. Journal of Pure and Applied Microbiology. 2019;13:2201-8.

28. Sahib KP, Rakesh KP, Pal SS, Apoorva S, Nidhi G. Awareness and knowledge of people towards probiotics products in Punjab region. International Journal of Applied Biology and Pharmaceutical Technology 2016;1:154-61.

29. Al-Nabulsi AA, Obiedat B, Ali R, Osaili TM, Bawadi $\mathrm{H}$, Abushelaibi A et al. Knowledge of probiotics and factors affecting their consumption by Jordanian College students. International Journal of Probiotics and Prebiotics. 2014;9(3):77-86.

30. Rijkers GT, Bimmel D, Grevers D, den Haan N, Hristova Y. Consumer perception of beneficial effects of probiotics for human health. Wageningen Academic Publishers. 2013;4:117-21.

31. Gnanamkonda V, Prasad S. Consumer awareness and consumption pattern of probiotic \& sugar free ice creams in Hyderabad \& Secunderabad. ZENITH International Journal of Business Economics \& Management Research. 2014;4(4):162-71.

32. Chin-Lee B, Curry WJ, Fetterman J, Graybill MA, Karpa K. Patient experience and use of probiotics in community-based health care settings. Patient Preference and Adherence. 2014;8:1513-20.

33. Khalesi S, Vandelanotte C, Thwaite T, Russell AMT, Dawson D, Williams SL. Awareness and Attitudes of Gut Health, Probiotics and Prebiotics in Australian Adults. Journal of Dietary Supplements. 2021;18(4):418-32.

34. Yilmaz-ersan L, Ozcan T, Akpinar-bayizit A. Food Science and Human Wellness Assessment of sociodemographic factors, health status and the knowledge on probiotic dairy products. Food Science and Human Wellness. 2020;9(3):272-9.

35. Loo EJ, Van Diem MNH, Pieniak Z, Verbeke W. Consumer attitudes, knowledge, and consumption of organic yogurt. Journal of Dairy Science. 2013;96(4):2118-29.

36. Nguyen M, Ferge KK, Vaughn AR, Burney W, Teng LH, Pan A et al. Probiotic Supplementation and Food Intake and Knowledge Among Patients and Consumers. Probiotics and Antimicrobial Proteins. 2019;1-10.

37. Hardia S. Designing of economical media for the growth of probiotics by using waste materials. Devi Ahiliya Vishwavidyalaya, Indore. 2012. http://hdl.handle.net/10603/238069. Accessed on 20 July 2021.

38. Panghal A, Janghu S, Virkar K, Gat Y, Kumar V, Chhikara N. Potential non-dairy probiotic products A healthy approach. Food Bioscience. 2018;21:80-9.

39. Ranadheera CS, Vidanarachchi JK, Rocha RS, Cruz AG, Ajlouni S. Probiotic Delivery through Fermentation: Dairy vs. Non-Dairy Beverages. Fermentation. 2017;1-17.

Cite this article as: Shireen A, Aneesh M.

Knowledge and consumption of probiotics and

prebiotics in India: a narrative review. Int J

Community Med Public Health 2021;8:5119-26. 